\title{
Focal adhesion kinases crucially regulate TGF $\beta$-induced migration and invasion of bladder cancer cells via Src kinase and E-cadherin
}

This article was published in the following Dove Press journal:

OncoTargets and Therapy

23 March 2017

Number of times this article has been viewed

\section{De-Bo Kong' \\ Feng Chen ${ }^{2}$ \\ $\mathrm{Ni} \mathrm{Sima}^{3}$}

'Department of Urology, The First Affiliated Hospital, School of Medicine, Zhejiang University, Hangzhou, Zhejiang, ${ }^{2}$ Department of Surgery, The Jiujiang Traditional Chinese Medicine Hospital, Jiujiang, Jiangxi, ${ }^{3}$ Women's Reproductive Health Key Laboratory of Zhejiang Province, Department of Gynecologic Oncology, Women's Hospital, School of Medicine, Zhejiang University, Hangzhou, Zhejiang, People's Republic of China
Correspondence: Ni Sima Women's Reproductive Health Key Laboratory of Zhejiang Province, Department of Gynecologic Oncology, Women's Hospital, School of Medicine, Zhejiang University, I Xueshi Road, Hangzhou, Zhejiang 310006, People's Republic of China

Tel $+8657 \mid 8706$ I50 I

Fax +86 57| 8706 I878 Email simani@I63.com
Abstract: Focal adhesion kinase (FAK) is a non-receptor protein-tyrosine kinase that is triggered off by special extracellular signals such as some growth factors and integrins. FAK is found in cell-matrix attachment sites and implicated in cell migration, invasion, movement, gene expression, survival and apoptosis. In this study, we aimed to investigate whether FAK plays a role in invasion and migration of bladder cancer cells. Using an FAK-specific small interfering RNA (siRNA) and an FAK inhibitor PF-228, we found that inhibition of FAK tyrosine phosphorylation or knockdown of FAK suppressed invasion and migration of bladder cancer cells. Src is an important mediator of FAK-regulated migratory and invasive activity. Tyrosine phosphorylation of Src and FAK is mutually dependent and plays a key role in transforming growth factor beta (TGF $\beta$ )-induced invasion and migration. E-cadherin acts downstream of FAK and is a critical negative regulator in FAK-regulated invasion and migration of bladder cancer cells. These findings imply that FAK is involved in oncogenic signaling of invasion and migration, which can be a novel therapeutic target to treat patients with bladder cancer.

Keywords: focal adhesion kinase, transforming growth factor beta, migration/invasion, bladder cancer, Src kinase, E-cadherin

\section{Introduction}

Bladder cancer is the eleventh most frequent malignancy, which accounts for $3.1 \%$ of all new cancer cases worldwide. Annually, 429,793 people suffer from this disease and $\sim 165,084$ people die from this disease. ${ }^{1}$ Moreover, bladder cancer is the most common malignancy in the urinary system and the seventh most common cancer in men all over the world. About $75 \%$ of patients who were diagnosed with bladder cancer that was limited to the mucosa or sub-mucosa, were grouped as non-muscle-invasive bladder cancer. However, $\sim 25 \%$ of patients were diagnosed with muscle-invasive bladder cancer, which implied that cancer cells had invaded into bladder detrusor. ${ }^{2}$ Moreover, $10 \%-20 \%$ of initially diagnosed non-muscle-invasive bladder tumors develop into muscle-invasive cancer after organ-preserving treatment, in 5 years. ${ }^{3}$ Approximately $25 \%$ of patients with muscle-invasive bladder cancer present with cancer cell metastasis to lymph nodes when radical cystectomy was performed, and it was thought that undetected metastases occurred in one-third of patients suffering from muscle-invasive bladder cancer at the time of the first diagnosis. ${ }^{4}$ Consequently, these facts underlined a critical need for the study on how to inhibit the metastasis and invasion of bladder cancer.

Focal adhesion kinase (FAK), a $125 \mathrm{kDa}$ protein, is one of a small and young family of structurally distinct protein tyrosine kinases without receptors such as FAK hereby accept the Terms. Non-commercial uses of the work are permitted without any further permission from Dove Medical Press Limited, provided the work is properly attributed. For permission for commercial use of this work, please see paragraphs 4.2 and 5 of our Terms (https://www.dovepress.com/terms.php). 
and PYK2, which can be triggered off by special extracellular signals such as some growth factors and integrins. ${ }^{5}$ The ptk2 gene, which encodes the messenger RNA (mRNA) of FAK, locates at 8q24.3, a site commonly amplified in several cancers such as serous ovarian cancer ${ }^{6}$ and gastric cancer. ${ }^{7}$ Therefore, the role of FAK in the malignant progression was assessed in several cancers.

Up till now, unusual increases in FAK expression were found in multiple types of cancers, ${ }^{8}$ such as lung cancer, ${ }^{9}$ ovarian cancer, ${ }^{10}$ breast cancer ${ }^{11}$ and cervical cancer. ${ }^{12}$ It is known that FAK is a scaffolding protein with several functional domains that links the input of transmembrane signals from growth factor receptors or integrins to several effector proteins within cells such as PI3K-AKT, Src and JNK. ${ }^{13}$ Therefore, FAK is important for signal transduction within the tumor microenvironment. ${ }^{14} \mathrm{FAK}$ proteins regulate several processes of cellular biology, which are important for the occurrence and progression of cancer, including cell survival and apoptosis, as well as adhesion, invasion and migration. ${ }^{15}$

Recent reports showed that FAK is overexpressed in bladder cancer, ${ }^{8}$ one of the most common tumors of the urinary system. However, no study up till now is available regarding whether FAK is related to invasion and metastasis of bladder cancer. In this study, we explored the role of FAK in the invasion and migration of bladder cancer cells.

\section{Materials and methods \\ Preparation and transfection of small interfering RNAs (siRNAs)}

As described previously, ${ }^{16}$ siRNAs were designed against Src (S: 5' ACU CGC CUU CUU AGA GUU U [dT][dT] 3', AS: 5' AAA CUC UAA GAA GGC GAGU [dT][dT] 3'), FAK (S: 5' UAA UAC UCG CUC CAU UGC ACC [dT][dT] 3', AS: 5' GGU GCA AUG GAG CGA GUA UUA [dT][dT] 3') and E-cadherin (S: $5^{\prime}$ GGG UUA AGC ACA ACA GCA A [dT][dT] 3', AS: 5' UUG CUG UUG UGC UUA ACC C $\left.[\mathrm{dT}][\mathrm{dT}] 3^{\prime}\right)$. The duplexes of the siRNAs were chemically synthesized (GeneChem, Shanghai, China) and used for transfecting bladder cancer cells by Lipofectamine ${ }^{\mathrm{TM}} 2000$ Transfection Reagent (Thermo Fisher Scientific, Waltham, MA, USA).

\section{Cell culture}

T24 and 5637 cells, two cell lines of human bladder cancer, were obtained from American Type Culture Collection. These cells were maintained in Dulbecco's Modified Eagle's Medium (GIBCO, Grand Island, NY, USA) supplemented with $10 \%$ fetal bovine serum (FBS) at $37^{\circ} \mathrm{C}$ under a humidified atmosphere containing $5 \% \mathrm{CO}_{2}$.

\section{Quantitative polymerase chain reaction (PCR)}

Total RNAs were prepared from the cells using TRIzol ${ }^{\circledR}$ reagent (Thermo Fisher Scientific) in accordance with the manufacturer's instructions. Primers were synthesized (Sangon, Shanghai, China) for quantitative PCR, which was performed with SYBR Green dye in an ABI7300 Real-time PCR System (Applied Biosystems, Foster City, CA, USA). The expression levels of target genes mRNA were relatively quantified with the $2^{-\Delta \Delta \mathrm{CT}}$ method. ${ }^{17}$

\section{Transwell assays}

Transwell cell migration assays were performed in 24-well Transwell plates (Costar, Cambridge, MA, USA) according to the slightly modified method of Pelletier et al. ${ }^{18}$ The lower chambers of the Transwell plates were filled with medium with $20 \%$ FBS, and the upper chambers of the Transwell plates were used for culturing cells. The upper and lower chambers were separated by membranes with a pore size of $8 \mu \mathrm{m}$. After 24 hours of incubation, the upper surface of the Transwell membranes was lightly scraped to clean nonmigrated cells, and the membrane was stained with crystal violet to count the migrated cells in the lower surface. Transwell cell invasion assays were performed in a similar way, but the upper chambers were coated with Matrigel.

\section{Western blotting}

Western blotting was carried out as described elsewhere. ${ }^{19}$ The treated cells were washed and collected and then resuspended in lysis buffer for further protein extraction. For each sample, $50 \mathrm{mg}$ of protein was loaded onto gel electrophoresis $(10 \%$ SDS-PAGE). ImageJ software (NIH, USA) was used to calculate the cumulative gray levels of each Western blotting band for further relative quantified analysis. The following antibodies were used as primary antibodies: $\beta$-actin (sc-1616-R) and GAPDH (sc-59540) from Santa Cruz (Santa Cruz, CA, USA) and E-cadherin (3195), pFAK (3283), FAK (3285), pSRC (2101) and Src (2109) from Cell Signaling (Beverly, MA, USA). Enhanced chemiluminescence (ECL; Pierce, Rockford, IL, USA) was used to visualize the bands.

\section{Statistical analyses}

Each experiment was done at least thrice. SPSS 12.0 (SPSS, USA) was used for analyzing the data. Student's $t$-test and one-way analysis of variance (ANOVA) were performed 
for statistical analyses of the data. For all statistical results, $P$-value $<0.05$ was considered statistically significant difference.

\section{Results}

\section{Reducing FAK impairs invasion and migration of bladder cancer cells}

To identify if reducing FAK impaired invasion and migration of bladder cancer cells, a specific siRNA duplex was used for knocking down FAK in bladder cancer cells, which was selected by quantitative PCR from several candidates. The results of Western blotting showed powerful interference effect of the selected siRNA duplex against the expression of FAK protein in bladder cancer T24 and 5637 cells as shown in Figure 1A and B. Further, the results of Transwell experiments showed that the selected siRNA duplex against FAK attenuated migratory and invasive ability of bladder cancer T24 cells (Figure 1C).

\section{Transforming growth factor beta (TGF $\beta$ ) induces FAK phosphorylation and enhances invasive and migratory potential of bladder cancer cells}

TGF $\beta$ is regarded as one of the important metastasis-related growth factors. We further determined the effects of TGF $\beta$ on FAK phosphorylation, as well as cell invasion and migration. The results of Western blotting showed that TGF $\beta(5 \mathrm{ng} / \mathrm{mL})$ did not change the expression of general FAK but significantly increased the expression of tyrosine-phosphorylated FAK in bladder cancer T24 and 5637 cells (Figure 2A and B). Src, an FAK-related kinase, was also tyrosine phosphorylated by TGF $\beta$ (Figure 2A and B). Moreover, TGF $\beta$ significantly
A

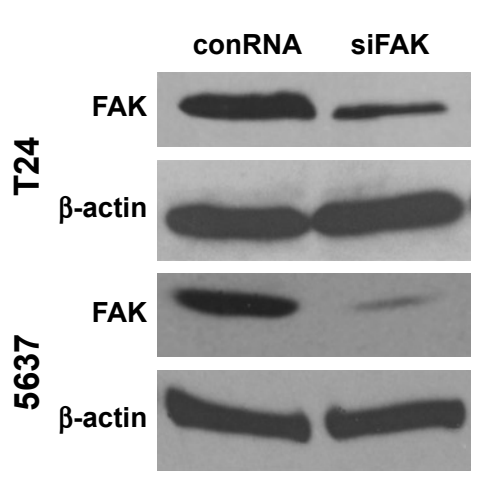

C

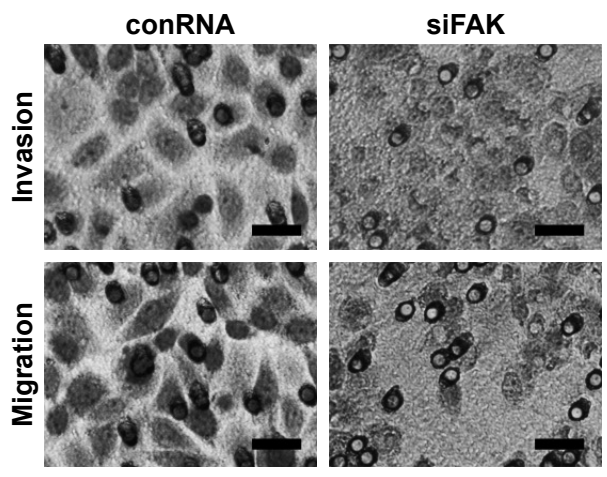

B

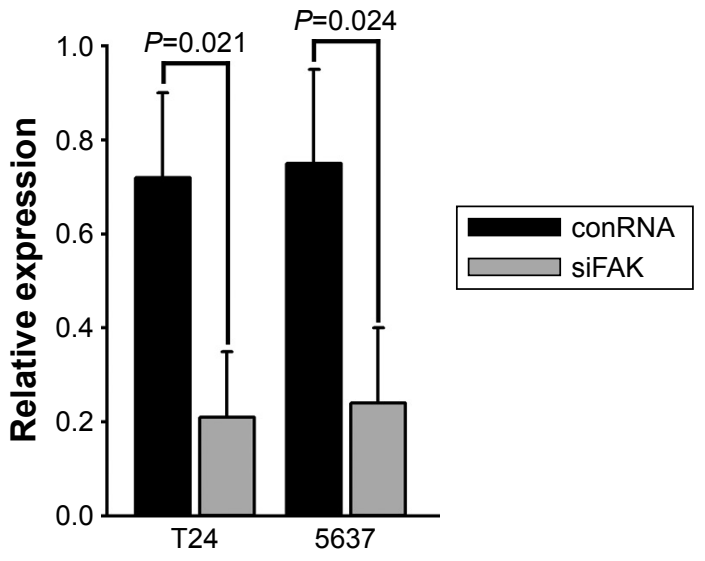

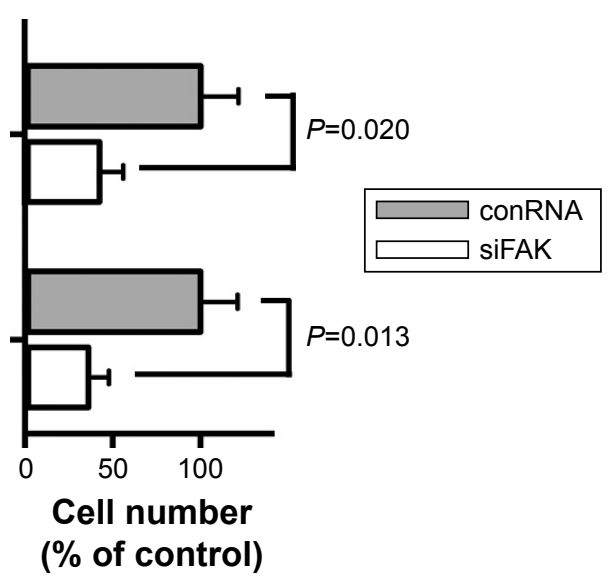

Figure I FAK was knocked down by a selected siRNA in bladder cancer cells.

Notes: T24 and 5637 cells were transfected with a selected siRNA. (A and B) Expression of FAK protein was measured by Western blotting. (C) Cell invasion and migration were measured by Transwell assays. Scale bar, $200 \mu \mathrm{m}$.

Abbreviations: FAK, focal adhesion kinase; siRNA, small interfering RNA; TGF $\beta$, transforming growth factor beta; conRNA, control RNA. 
A
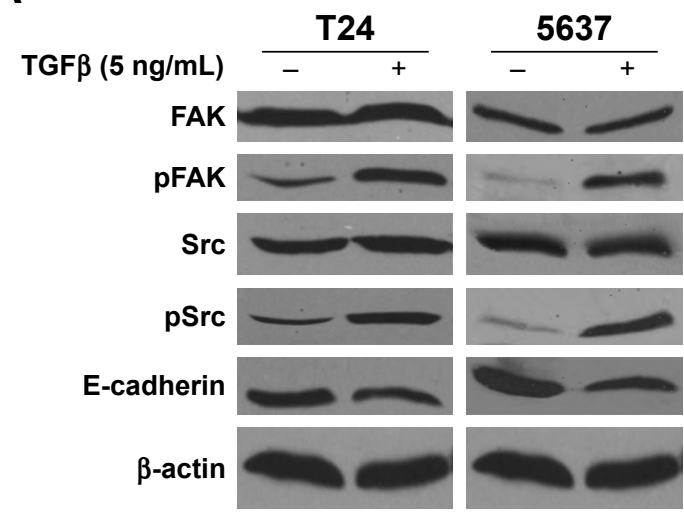

C

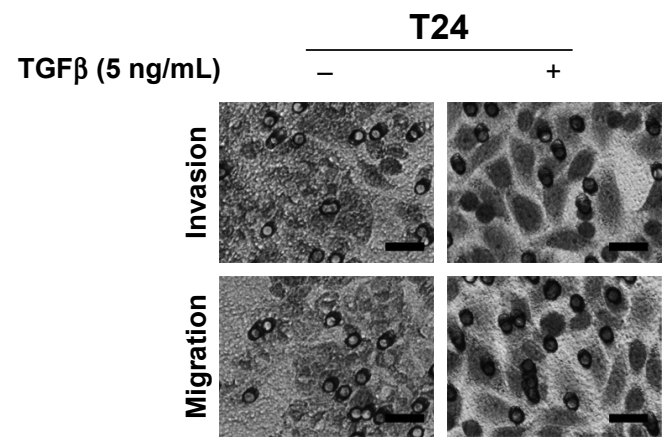

B
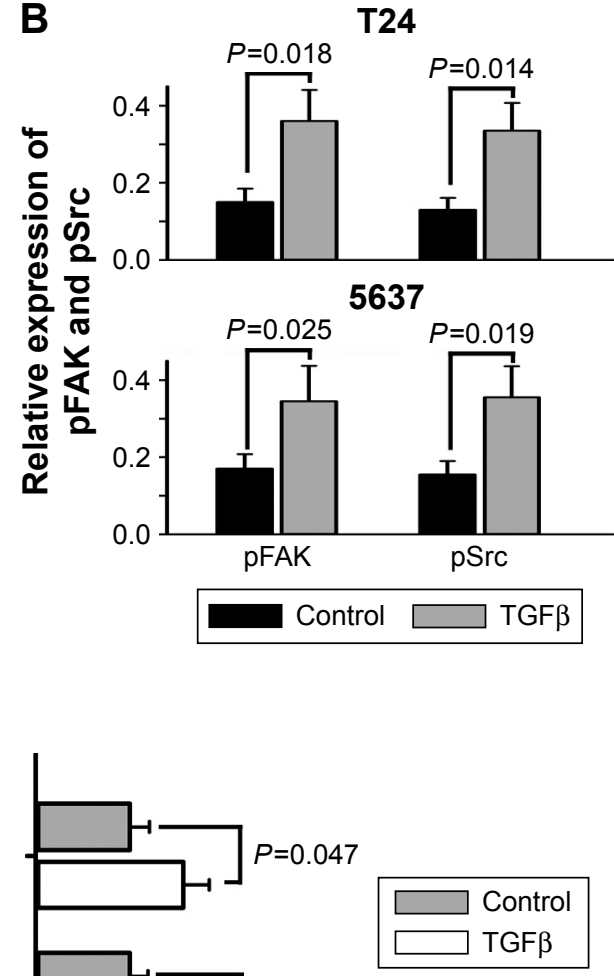

Figure 2 Effect of TGF $\beta$ on FAK phosphorylation and migratory and invasive potential of bladder cancer cells.

Notes: T24 and 5637 cells were treated with $5 \mathrm{ng} / \mathrm{mL}$ TGF $\beta$. (A and B) Expression of Src, pSrc, FAK, pFAK and E-cadherin was measured by Western blotting. (C) Cell invasion and migration were examined by Transwell assays. Scale bar, $200 \mu \mathrm{m}$.

Abbreviations: FAK, focal adhesion kinase; TGF $\beta$, transforming growth factor beta.

decreased the expression of E-cadherin, a metastasis-related protein (Figure 2A). The results of Transwell experiments showed that TGF $\beta$ significantly increased cell migration and invasion of bladder cancer T24 cells (Figure 2C).

\section{Inhibition of FAK phosphorylation reduces TGF $\beta$-induced migration and invasion of bladder cancer cells}

To further explore if inhibition of FAK phosphorylation regulated TGF $\beta$-induced migration and invasion of bladder cancer cells, we employed PF-228 (Sigma, USA), a smallmolecule selective inhibitor of FAK, to reduce tyrosine phosphorylation level of FAK. The results of Western blotting showed that PF-228 $(10 \mu \mathrm{M})$ significantly decreased TGF $\beta$-stimulated tyrosine phosphorylation of not only Src but also FAK (Figure 3A and B). The results of Transwell experiments showed that $\mathrm{PF}-228$ reduced TGF $\beta$-induced cell migration and invasion of T24 cells (Figure 3C).
Src is an important mediator of FAK-regulated invasive and migratory activity of bladder cancer cells

To further study if suppression of Src phosphorylation regulated TGF $\beta$-induced migration and invasion of bladder cancer cells, PP2 (Sigma, USA), a selective Src family tyrosine kinase inhibitor, was used for reducing tyrosine phosphorylation level of Src. The results of Western blotting showed that PP2 $(10 \mu \mathrm{M})$ significantly cut down TGF $\beta$-stimulated tyrosine phosphorylation levels of not only FAK but also Src (Figure 4A and B), which was similar to PF-228. The results of Transwell experiments showed that PP2 reduced TGF $\beta$-induced cell migration and invasion of T24 cells (Figure 4C). To further study the relationship of tyrosine phosphorylation of Src and that of FAK, a specific siRNA duplex against Src was employed to knock down Src in bladder cancer cells. The results of Western blotting showed that the siRNA not only knocked down Src but also reduced 
A

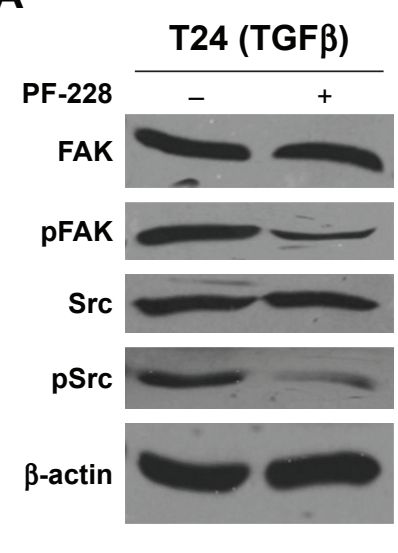

5637 (TGF $\beta$ )

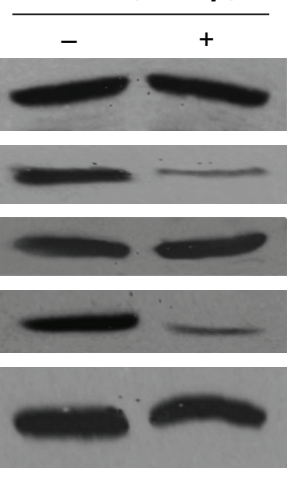

B

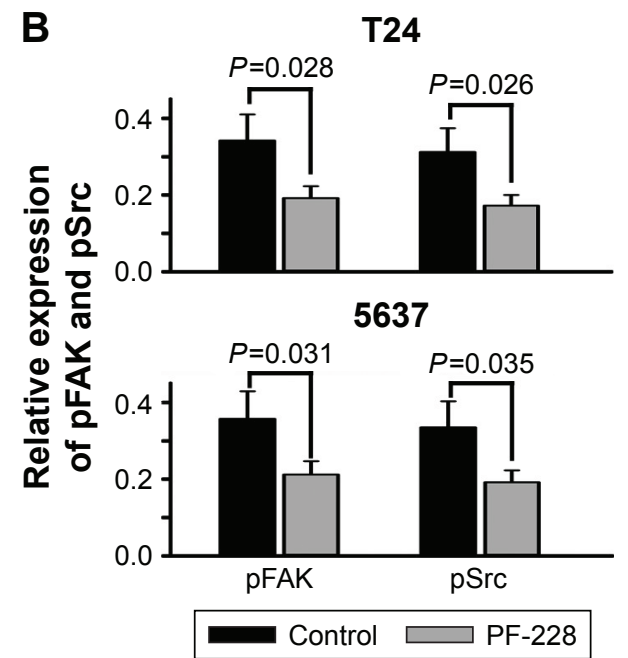

C

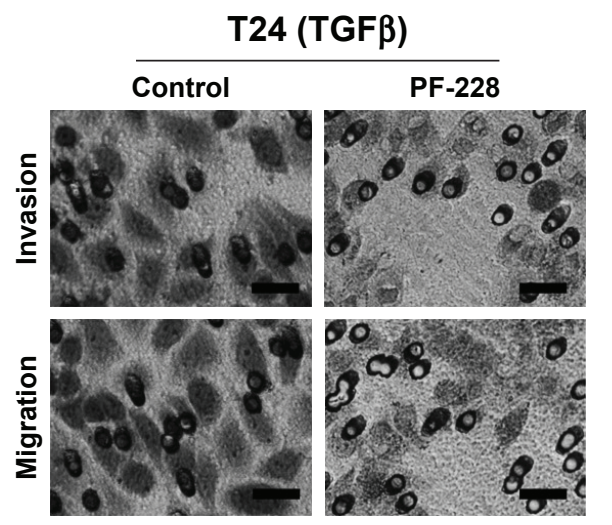

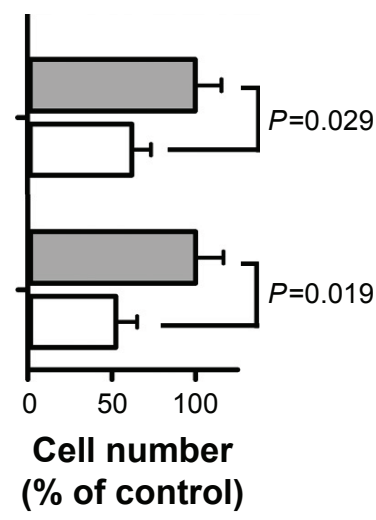

Figure 3 Suppression of FAK phosphorylation reduces TGF $\beta$-induced migration and invasion of bladder cancer cells.

Notes: T24 and 5637 cells were treated with $5 \mathrm{ng} / \mathrm{mL}$ TGF $\beta$ and $10 \mu \mathrm{M}$ PF-228. (A and B) Expression of Src, pSrc, FAK and pFAK was examined by Western blotting. (C) Cell invasion and migration were measured by Transwell assays. Scale bar, $200 \mu \mathrm{m}$.

Abbreviations: FAK, focal adhesion kinase; TGF $\beta$, transforming growth factor beta.

tyrosine-phosphorylated levels of FAK (Figure 4D and E). The results of Transwell experiments demonstrated that the siRNA significantly reduced TGF $\beta$-induced cell migration and invasion of T24 cells (Figure 4F).

\section{E-cadherin regulates invasive and migratory capability of bladder cancer cells as a downstream signal of FAK}

The loss of E-cadherin was one of the most important risk factors for metastasis of several carcinomas. Therefore, we further studied whether E-cadherin regulated the invasive and migratory capability of bladder cancer cells as a downstream signal of FAK. Western blotting analysis showed that E-cadherin was significantly upregulated when FAK was repressed by PF-228 or specific siRNA in bladder cancer T24 and 5637 cells (Figure 5A and B). On the other hand, the expression of not only tyrosine-phosphorylated but also general FAK was not regulated via the knockdown of the
E-cadherin by specific siRNA (Figure 5C and D). The results of Transwell experiments demonstrated that the inhibiting effect of PF-228 on TGF $\beta$-stimulated cell invasion and migration was reversed by the knockdown of the E-cadherin in T24 cells (Figure 5E and F).

\section{Discussion}

In 1992, FAK was first found by Schaller et $\mathrm{al}^{20}$ and identified as a $125 \mathrm{kDa}$ substrate of $\mathrm{v}$-Src in chicken embryo fibroblasts. They found that FAK was a major phosphotyrosinecontaining protein and tyrosine phosphorylated in the cells that were transformed by v-Src. The protein was named as focal adhesion kinase for its location to focal adhesions. Another research team found that tyrosine phosphorylation of FAK was one of the vital first steps in intracellular signaling transduction pathways in reply to the stimuli from the extracellular matrix. ${ }^{21}$ Subsequently, it was found by Schaller et $\mathrm{al}^{22}$ in 1994 that integrin-linked FAK exhibited tyrosine 
phosphorylation depending on extracellular matrix and physically associated to Src through their SH2 domains. Moreover, they also found that Tyr397 was a major site for FAK autophosphorylation. These findings suggested an elementary model that described the mechanisms of FAK activation and the mutual regulation of FAK and Src. Currently, it was found that FAK regulates cell migration, invasion, movement, gene expression, survival and apoptosis. ${ }^{8}$ The goal of this study was to explore whether suppression of FAK impaired migration and invasion of bladder cancer cells.

RNA interference (RNAi) is a powerful tool for silencing specific genes by degrading the target mRNA. Several studies $^{23-27}$ have shown that expression of FAK was downregulated by some specific siRNAs targeting mRNA
A

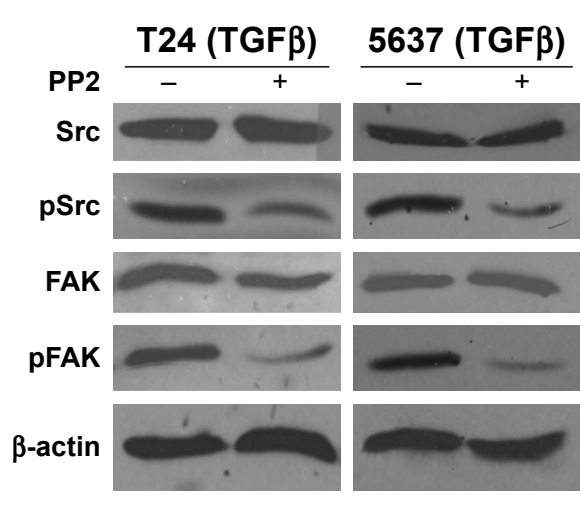

C

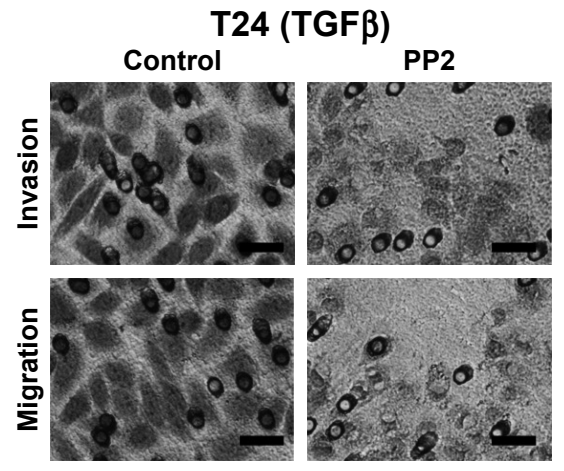

D

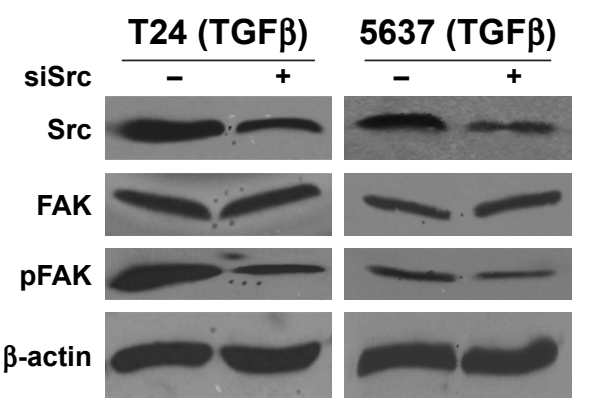

B
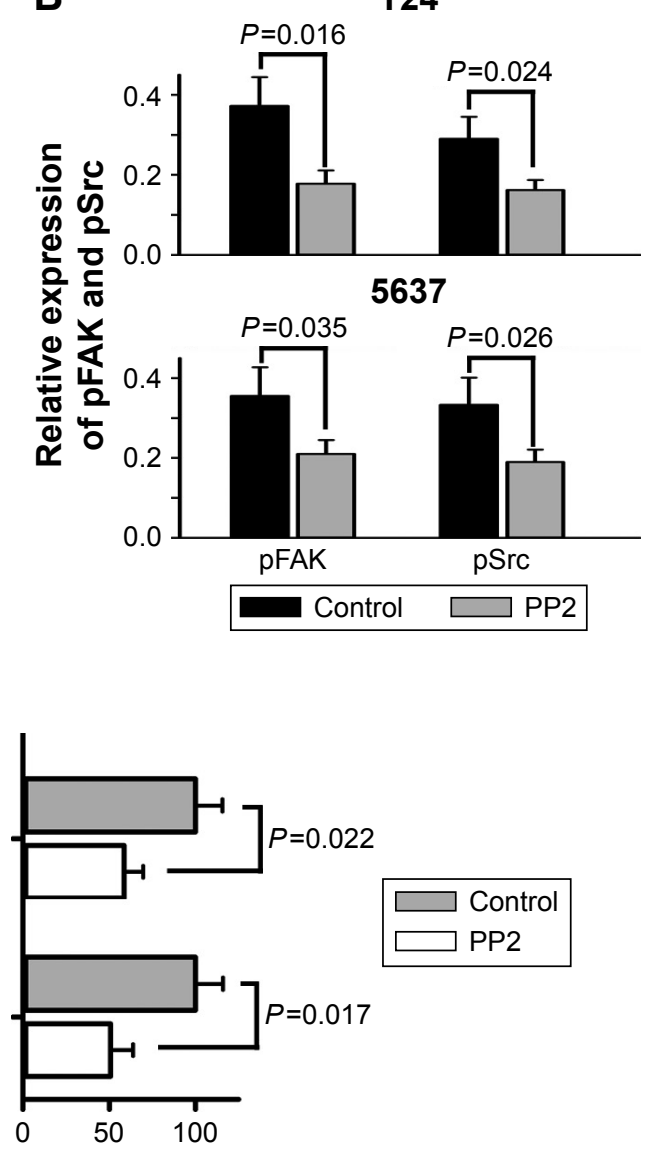

Cell number (\% of control)

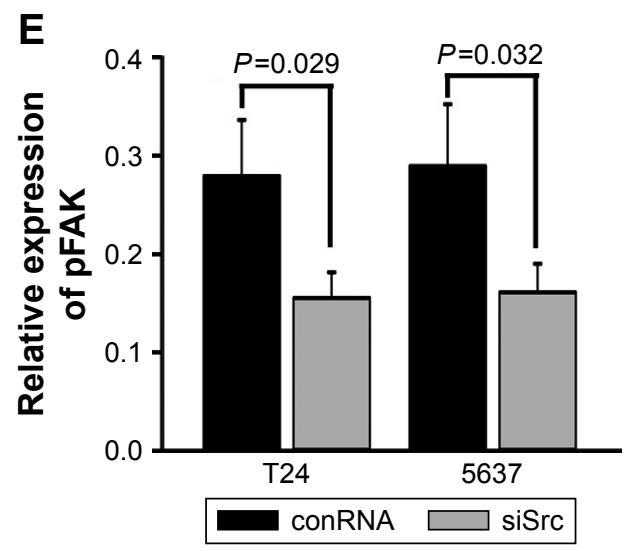




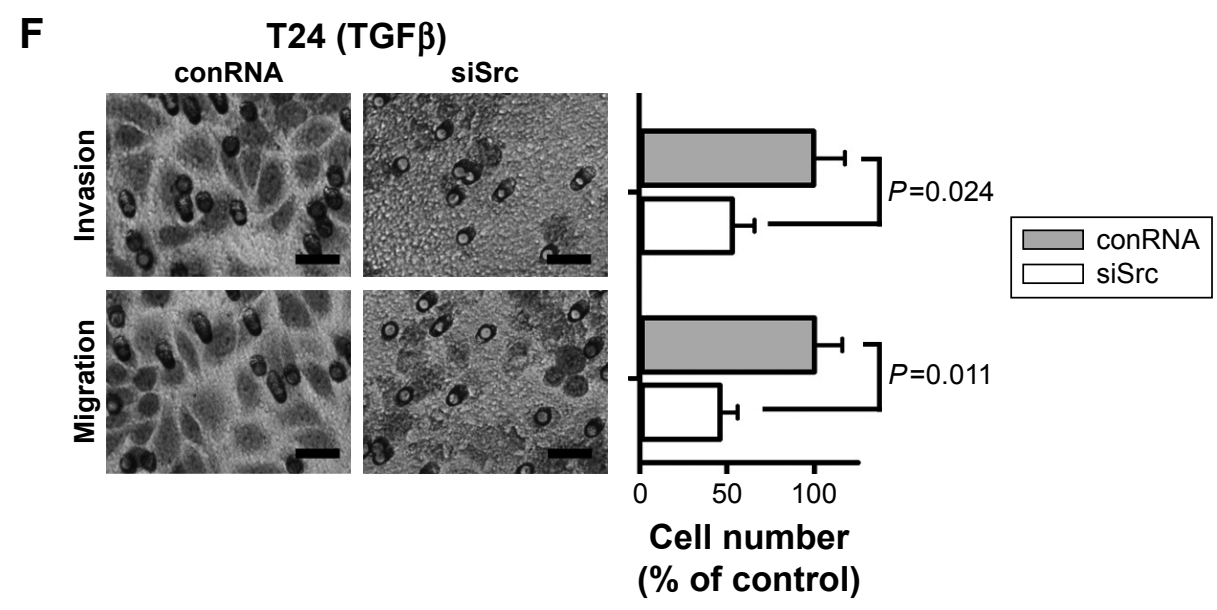

Figure 4 The role of Src in FAK-regulated migratory and invasive activity of bladder cancer cells.

Notes: T24 and 5637 cells were treated with $10 \mu \mathrm{M}$ PP2 or siRNA against Src. (A, B, D and E) Expression of Src, pSrc, FAK and pFAK was measured by Western blotting. (C and F) Cell invasion and migration were examined by Transwell assays. Scale bar, $200 \mu \mathrm{m}$.

Abbreviations: FAK, focal adhesion kinase; siRNA, small interfering RNA; TGF $\beta$, transforming growth factor beta; conRNA, control RNA.

A

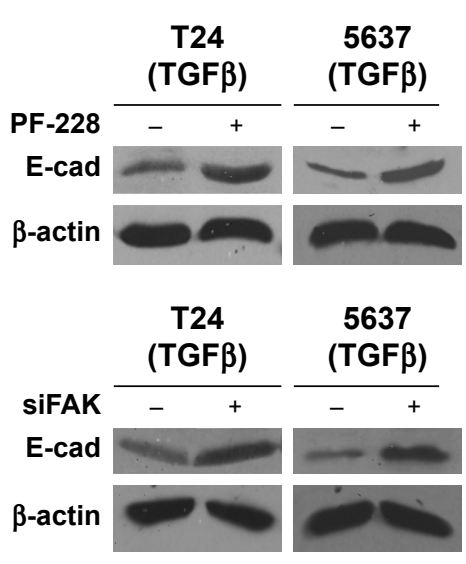

C

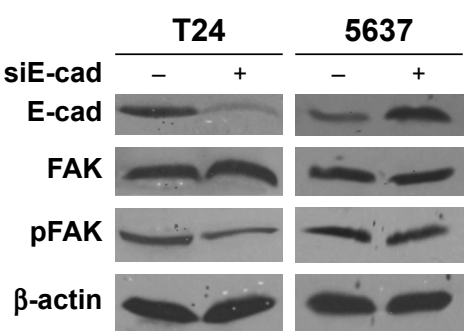

$\mathbf{E}$

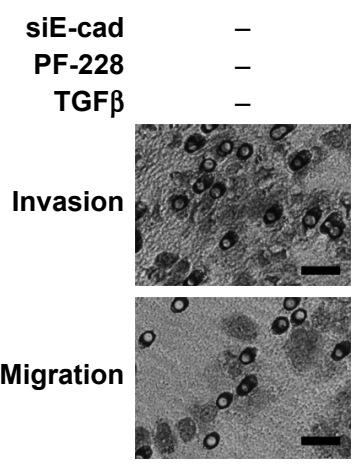

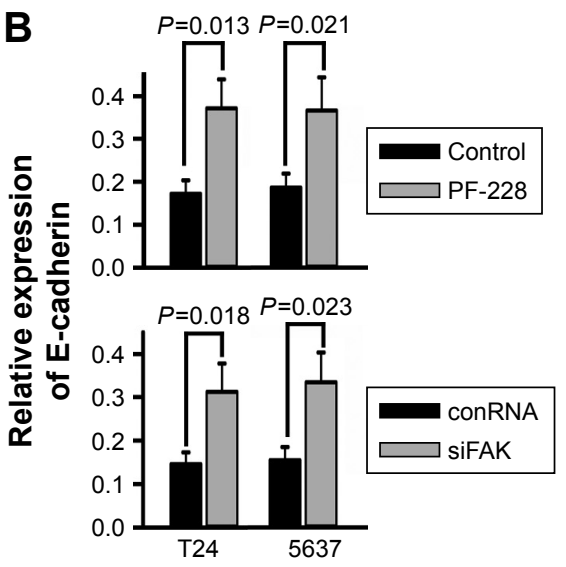

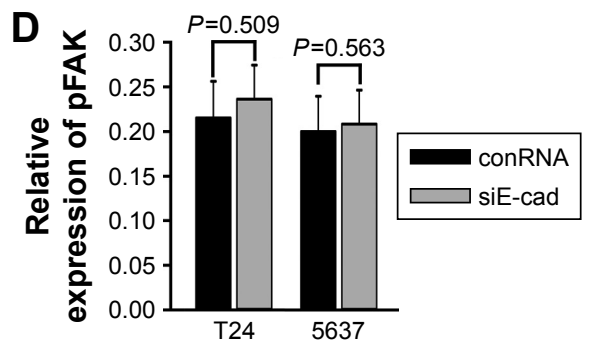

T24

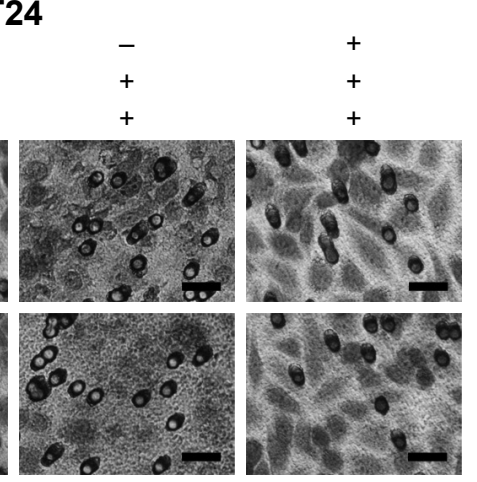

Figure 5 (Continued) 

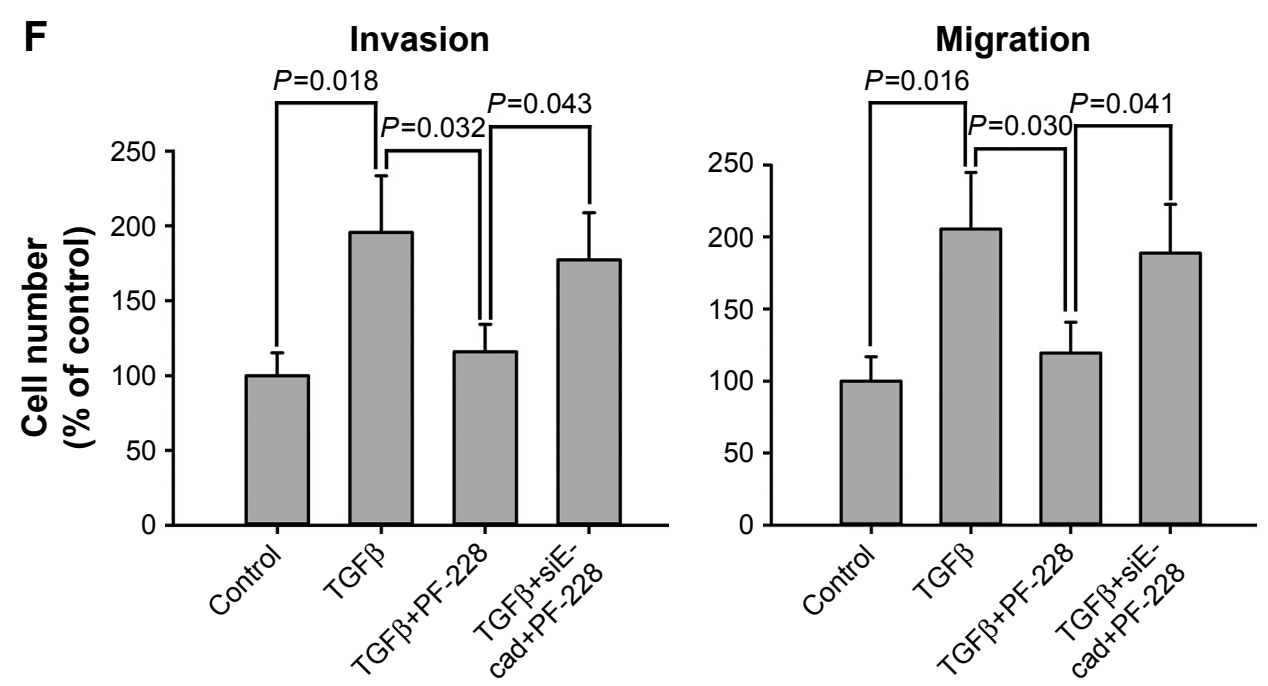

Figure $\mathbf{5}$ The role of E-cadherin in FAK-regulated migratory and invasive activity of bladder cancer cells.

Notes: T24 and 5637 cells were treated with siRNA against E-cadherin or FAK. (A-D) Expression of E-cadherin, FAK and pFAK was measured by Western blotting. (E and F) Cell invasion and migration were measured by Transwell assays. Scale bar, $200 \mu \mathrm{m}$.

Abbreviations: FAK, focal adhesion kinase; siRNA, small interfering RNA; TGF $\beta$, transforming growth factor beta; E-cad, E-cadherin; conRNA, control RNA.

of $p t k 2$ gene. Hence, RNAi was employed to explore the role of suppressing FAK on the migration and invasion of bladder cancer cells. In the further experiments, the results of knockdown demonstrated that siRNAs against ptk2 gene significantly inhibited both the protein of FAK and the mRNA of $p t k 2$ gene.

FAK is a focal adhesion-related protein and has been shown to be associated with migration and invasion since its initial discovery in $1992 .{ }^{20,21}$ Up to now, FAK was implicated as an important regulator of invasion and migration of several cancers such as colon cancer, ${ }^{28}$ ovarian cancer, ${ }^{29}$ lung cancer, ${ }^{30}$ tongue squamous cancer ${ }^{31}$ and thyroid cancer. ${ }^{32}$ Our results showed that inhibiting FAK expression via RNAi significantly attenuated invasion and migration of bladder cancer cells.

It is known that FAK is a vital mediator of TGF $\beta$ signaling. ${ }^{33}$ Walsh et al ${ }^{34}$ suggested that TGF $\beta$ stimulated FAK synthesis as well as FAK phosphorylation through p38- and Smad-dependent pathways. However, most researchers found that TGF $\beta$ regulated FAK mainly via FAK phosphorylation. ${ }^{35-37}$ Our results showed that TGF $\beta$ stimulated FAK phosphorylation rather than FAK synthesis. Moreover, TGF $\beta$ enhanced the migration and invasion of bladder cancer cells. Because PF-228 is a highly selective small molecular inhibitor of FAK and can inhibit FAK phosphorylation at Tyr397, ${ }^{38}$ we employed PF-228 as a tool to inhibit FAK phosphorylation in TGF $\beta$-stimulated bladder cancer cells. The experimental results showed that PF-228 was able to inhibit TGF $\beta$-stimulated tyrosine phosphorylation of Src and FAK and suppress invasion and migration of bladder cancer cells.
Src was identified as an FAK-related protein since its initial discovery in $1992 .{ }^{20,21}$ In effect, input signaling from growth factor receptors and integrins leads to FAK autophosphorylation at Tyr397 where Src links to FAK subsequently. Subsequently, FAK proteins are phosphorylated at Y576 and Y577, and then, FAK-Src complexes are formed and play a key role in mediating the signaling from growth factor receptors and integrins to downstream molecules such as ERKs and paxillin. ${ }^{39,40}$ So, Src protein is one of the most important regulators in FAK-associated signal transduction. PP2 is an inhibitor of Src family tyrosine kinases and shows $>10,000$-fold selection over JAK2 and ZAP-70.$^{41} \mathrm{PP} 2$ is able to block Tyr416 phosphorylation of Src. We employed PP2 as a tool to inhibit Src phosphorylation in TGF $\beta$ stimulated bladder cancer cells. The experimental results showed that PP2 was able to inhibit tyrosine-phosphorylated levels of not only Src but also FAK in bladder cancer cells stimulated by TGF $\beta$. PP 2 also inhibited invasion and migration of TGF $\beta$-stimulated bladder cancer cells. Moreover, knockdown of Src not only decreased the protein expression of Src but also inhibited tyrosine phosphorylation of FAK. It was no surprise that knockdown of Src suppressed invasion and migration of TGF $\beta$-stimulated bladder cancer cells.

E-cadherin is an invasion and tumor suppressor protein, which is a prototype of the "classical" type 1 cadherins and one of the most important components of adherens junctions known as intercellular adhesions. ${ }^{42}$ The loss of E-cadherin regulated FAK signaling through $\alpha 5$-integrin upregulation in trophoblast cells. ${ }^{43}$ Our results showed that not only FAK inhibitor PF-228 but also siRNA against FAK were 
able to increase E-cadherin expression in TGF $\beta$-stimulated bladder cancer cells. However, knockdown of E-cadherin did not change general and tyrosine-phosphorylated FAK. Moreover, the results of Transwell experiments showed that FAK inhibitor PF-228 suppressed TGF $\beta$-stimulated invasion and migration of bladder cancer cells, which was able to be restored via knockdown of E-cadherin.

We demonstrated that FAK was a vital regulatory molecule of invasion and migration of bladder cancer cells. Knockdown of FAK inhibited invasion and migration of bladder cancer cells. TGF $\beta$ induced FAK phosphorylation and enhanced migratory and invasive potential. Moreover, suppression of FAK phosphorylation reduced TGF $\beta$-induced invasion and migration. Src was one of the most important mediators of FAK-related migratory and invasive activity. Tyrosine phosphorylation of FAK and Src was mutually dependent and played a key role in TGF $\beta$-induced invasion and migration. E-cadherin acted downstream of FAK and was a critical negative regulator in FAK-regulated invasion and migration of bladder cancer cells. These results suggested a mechanism for invasion and migration involving FAK-related oncogenic signal as well as a novel therapeutic target and strategy for treating patients who develop bladder cancer.

\section{Acknowledgments}

This research was supported by the Zhejiang Provincial Medical Science and Technology Program (Nos 2013RCA014 and 2014KYA117), the Zhejiang Provincial Natural Science Foundation of China (No LY12H16020) and the National Natural Science Foundation of China (No 81272862).

\section{Disclosure}

The authors report no conflicts of interest in this work.

\section{References}

1. Jemal A, Bray F, Center MM, Ferlay J, Ward E, Forman D. Global cancer statistics. CA Cancer J Clin. 2011;61(2):69-90.

2. Antoni S, Ferlay J, Soerjomataram I, Znaor A, Jemal A, Bray F. Bladder cancer incidence and mortality: a global overview and recent trends. Eur Urol. 2017;71(1):96-108.

3. Black PC. Fine-tuning risk stratification for non-muscle-invasive bladder cancer. Eur Urol. 2016;69(1):70-71.

4. Prout GR Jr, Griffin PP, Shipley WU. Bladder carcinoma as a systemic disease. Cancer. 1979;43(6):2532-2539.

5. Lechertier T, Hodivala-Dilke K. Focal adhesion kinase and tumour angiogenesis. J Pathol. 2012;226(2):404-412.

6. Okamoto H, Yasui K, Zhao C, Arii S, Inazawa J. PTK2 and EIF3S3 genes may be amplification targets at 8q23-q24 and are associated with large hepatocellular carcinomas. Hepatology. 2003;38(5):1242-1249.

7. Park JH, Lee BL, Yoon J, et al. Focal adhesion kinase (FAK) gene amplification and its clinical implications in gastric cancer. Hum Pathol. 2010;41(12):1664-1673.

8. Sulzmaier FJ, Jean C, Schlaepfer DD. FAK in cancer: mechanistic findings and clinical applications. Nat Rev Cancer. 2014;14(9):598-610.
9. Lu H, Wang L, Gao W, et al. IGFBP2/FAK pathway is causally associated with dasatinib resistance in non-small cell lung cancer cells. Mol Cancer Ther. 2013;12(12):2864-2873.

10. Cancer Genome Atlas Research Network. Integrated genomic analyses of ovarian carcinoma. Nature. 2011;474(7353):609-615.

11. Cancer Genome Atlas Network. Comprehensive molecular portraits of human breast tumours. Nature. 2012;490(7418):61-70.

12. Oktay MH, Oktay K, Hamele-Bena D, Buyuk A, Koss LG. Focal adhesion kinase as a marker of malignant phenotype in breast and cervical carcinomas. Hum Pathol. 2003;34(3):240-245.

13. Wendt MK, Smith JA, Schiemann WP. Transforming growth factorbeta-induced epithelial-mesenchymal transition facilitates epidermal growth factor-dependent breast cancer progression. Oncogene. 2010; 29(49):6485-6498.

14. Schober M, Fuchs E. Tumor-initiating stem cells of squamous cell carcinomas and their control by TGF-beta and integrin/focal adhesion kinase (FAK) signaling. Proc Natl Acad Sci U S A. 2011;108(26): 10544-10549.

15. Luo M, Guan JL. Focal adhesion kinase: a prominent determinant in breast cancer initiation, progression and metastasis. Cancer Lett. 2010; 289(2):127-139.

16. Sima N, Wang W, Kong D, et al. RNA interference against HPV16 E7 oncogene leads to viral E6 and E7 suppression in cervical cancer cells and apoptosis via upregulation of Rb and p53. Apoptosis. 2008;13(2): 273-281.

17. Li BH, Zhou JS, Ye F, et al. Reduced miR-100 expression in cervical cancer and precursors and its carcinogenic effect through targeting PLK1 protein. Eur J Cancer. 2011;47(14):2166-2174.

18. Pelletier AJ, Kunicki T, Quaranta V. Activation of the integrin alpha V beta 3 involves a discrete cation-binding site that regulates conformation. J Biol Chem. 1996;271(3):1364-1370.

19. Sima N, Wang S, Wang W, et al. Antisense targeting human papillomavirus type 16 E6 and E7 genes contributes to apoptosis and senescence in SiHa cervical carcinoma cells. Gynecol Oncol. 2007;106(2): 299-304.

20. Schaller MD, Borgman CA, Cobb BS, Vines RR, Reynolds AB, Parsons JT. pp125FAK a structurally distinctive protein-tyrosine kinase associated with focal adhesions. Proc Natl Acad Sci U S A. 1992; 89(11):5192-5196.

21. Hanks SK, Calalb MB, Harper MC, Patel SK. Focal adhesion proteintyrosine kinase phosphorylated in response to cell attachment to fibronectin. Proc Natl Acad Sci US A. 1992;89(18):8487-8491.

22. Schaller MD, Hildebrand JD, Shannon JD, Fox JW, Vines RR, Parsons JT. Autophosphorylation of the focal adhesion kinase, pp125FAK, directs SH2-dependent binding of pp60src. Mol Cell Biol. 1994;14(3):1680-1688.

23. Clemente CF, Tornatore TF, Theizen TH, et al. Targeting focal adhesion kinase with small interfering RNA prevents and reverses load-induced cardiac hypertrophy in mice. Circ Res. 2007;101(12):1339-1348.

24. Duxbury MS, Ito H, Benoit E, Zinner MJ, Ashley SW, Whang EE. RNA interference targeting focal adhesion kinase enhances pancreatic adenocarcinoma gemcitabine chemosensitivity. Biochem Biophys Res Commun. 2003;311(3):786-792.

25. Chan KT, Cortesio CL, Huttenlocher A. FAK alters invadopodia and focal adhesion composition and dynamics to regulate breast cancer invasion. J Cell Biol. 2009;185(2):357-370.

26. Thamilselvan V, Craig DH, Basson MD. FAK association with multiple signal proteins mediates pressure-induced colon cancer cell adhesion via a Src-dependent PI3K/Akt pathway. FASEB J. 2007;21(8): 1730-1741.

27. Shi Q, Bao S, Song L, et al. Targeting SPARC expression decreases glioma cellular survival and invasion associated with reduced activities of FAK and ILK kinases. Oncogene. 2007;26(28):4084-4094.

28. Van Slambrouck S, Grijelmo C, De Wever O, et al. Activation of the FAKsrc molecular scaffolds and p130Cas-JNK signaling cascades by alpha1integrins during colon cancer cell invasion. Int J Oncol. 2007;31(6): 1501-1508. 
29. Sood AK, Coffin JE, Schneider GB, et al. Biological significance of focal adhesion kinase in ovarian cancer: role in migration and invasion. Am J Pathol. 2004;165(4):1087-1095.

30. Meng XN, Jin Y, Yu Y, et al. Characterisation of fibronectin-mediated FAK signalling pathways in lung cancer cell migration and invasion. Br J Cancer. 2009;101(2):327-334.

31. Ho YT, Yang JS, Li TC, et al. Berberine suppresses in vitro migration and invasion of human SCC-4 tongue squamous cancer cells through the inhibitions of FAK, IKK, NF-kappaB, u-PA and MMP-2 and -9. Cancer Lett. 2009;279(2):155-162.

32. Nowicki TS, Zhao H, Darzynkiewicz Z, et al. Downregulation of uPAR inhibits migration, invasion, proliferation, FAK/PI3K/Akt signaling and induces senescence in papillary thyroid carcinoma cells. Cell Cycle. 2011;10(1):100-107.

33. Leask A. Focal adhesion kinase: a key mediator of transforming growth factor beta signaling in fibroblasts. Adv Wound Care (New Rochelle). 2013;2(5):247-249.

34. Walsh MF, Ampasala DR, Hatfield J, et al. Transforming growth factor-beta stimulates intestinal epithelial focal adhesion kinase synthesis via Smad- and p38-dependent mechanisms. Am J Pathol. 2008; 173(2):385-399.

35. Wang H, Radjendirane V, Wary KK, Chakrabarty S. Transforming growth factor beta regulates cell-cell adhesion through extracellular matrix remodeling and activation of focal adhesion kinase in human colon carcinoma Moser cells. Oncogene. 2004;23(32):5558-5561.

36. Xu Z, Ma DZ, Wang LY, Su JM, Zha XL. Transforming growth factor-beta1 stimulated protein kinase B serine-473 and focal adhesion kinase tyrosine phosphorylation dependent on cell adhesion in human hepatocellular carcinoma SMMC-7721 cells. Biochem Biophys Res Commun. 2003;312(2):388-396.
37. Wang SE, Xiang B, Zent R, Quaranta V, Pozzi A, Arteaga CL. Transforming growth factor beta induces clustering of HER2 and integrins by activating Src-focal adhesion kinase and receptor association to the cytoskeleton. Cancer Res. 2009;69(2):475-482.

38. Li S, Hua ZC. FAK expression regulation and therapeutic potential. Adv Cancer Res. 2008;101:45-61.

39. Schaller MD. Cellular functions of FAK kinases: insight into molecular mechanisms and novel functions. J Cell Sci. 2010;123(pt 7): 1007-1013.

40. Mitra SK, Schlaepfer DD. Integrin-regulated FAK-Src signaling in normal and cancer cells. Curr Opin Cell Biol. 2006;18(5):516-523.

41. Chiang GJ, Billmeyer BR, Canes D, et al. The src-family kinase inhibitor PP2 suppresses the in vitro invasive phenotype of bladder carcinoma cells via modulation of Akt. BJU Int. 2005;96(3):416-422.

42. Serrels A, Canel M, Brunton VG, Frame MC. Src/FAK-mediated regulation of E-cadherin as a mechanism for controlling collective cell movement: insights from in vivo imaging. Cell Adh Migr. 2011;5(4): 360-365.

43. Arimoto-Ishida E, Sakata M, Sawada K, et al. Up-regulation of alpha5integrin by E-cadherin loss in hypoxia and its key role in the migration of extravillous trophoblast cells during early implantation. Endocrinology. 2009;150(9):4306-4315.
OncoTargets and Therapy

\section{Publish your work in this journal}

OncoTargets and Therapy is an international, peer-reviewed, open access journal focusing on the pathological basis of all cancers, potential targets for therapy and treatment protocols employed to improve the management of cancer patients. The journal also focuses on the impact of management programs and new therapeutic agents and protocols on

\section{Dovepress}

patient perspectives such as quality of life, adherence and satisfaction The manuscript management system is completely online and includes a very quick and fair peer-review system, which is all easy to use. Visit http://www.dovepress.com/testimonials.php to read real quotes from published authors. 